\title{
Utility of the narrow-band imaging international colorectal endoscopic classification for optical diagnosis of colorectal polyp histology in clinical practice: a retrospective study
}

Yasuhiko Hamada ${ }^{* *} \mathbb{0}$, Kyosuke Tanaka², Masaki Katsurahara², Noriyuki Horiki², Reiko Yamada', Tomomi Yamada $^{3}$ and Yoshiyuki Takei ${ }^{1}$

\begin{abstract}
Background: Narrow-band imaging (NBI) highlights the surface structures and vessels of colorectal polyps and is useful for determining the polyp histology. The narrow-band imaging international colorectal endoscopic (NICE) classification is a diagnostic tool for determining colorectal polyp histology based on NBI without optical magnification. In this study, we aimed to investigate the value of each type of the NICE classification for determining colorectal polyp histology using endoscopy data accumulated in a clinical setting.

Methods: Endoscopy data for 534 colorectal polyps (316 patients) treated at our facility were retrospectively analyzed. First, we investigated the diagnostic performance of each type of the NICE classification for the optical diagnosis of colorectal polyp histology. The procedures were performed by experienced endoscopists using high-definition colonoscopy without optical magnification. Second, inter-observer and intra-observer agreements were assessed after providing experts and non-experts with a short lecture on the NICE classification. Using 50 fine NBI images of colorectal polyps without optical magnification, the inter-observer and intra-observer agreements between five experts and five non-experts were assessed.
\end{abstract}

Results: The sensitivity, specificity, and accuracy values were 86.0\%, 99.6\%, and 98.5\% for NICE type 1 lesions; 99.2\%, 85.2\%, and 97.8\% for NICE type 2 lesions; and 81.8\%, 99.6\%, and 99.3\% for NICE type 3 lesions, respectively. The interobserver and intra-observer agreements ranged from substantial to excellent for both experts and non-experts.

Conclusions: The NICE classification had good diagnostic ability in terms of determining the polyp histology and demonstrated a high level of reproducibility among experts and non-experts. Thus, the NICE classification is a useful clinical tool that can be used without optical magnification.

Keywords: Colonoscopy, Colorectal polyp, Narrow-band imaging, NICE classification, Optical diagnosis

\footnotetext{
*Correspondence: y-hamada@clin.medic.mie-u.ac.jp

1 Department of Gastroenterology and Hepatology, Mie University

Hospital, 2-174 Edobashi, Tsu, Mie 514-8507, Japan

Full list of author information is available at the end of the article
}

(C) The Author(s) 2021. Open Access This article is licensed under a Creative Commons Attribution 4.0 International License, which permits use, sharing, adaptation, distribution and reproduction in any medium or format, as long as you give appropriate credit to the original author(s) and the source, provide a link to the Creative Commons licence, and indicate if changes were made. The images or other third party material in this article are included in the article's Creative Commons licence, unless indicated otherwise in a credit line to the material. If material is not included in the article's Creative Commons licence and your intended use is not permitted by statutory regulation or exceeds the permitted use, you will need to obtain permission directly from the copyright holder. To view a copy of this licence, visit http://creativecommons.org/licenses/by/4.0/. The Creative Commons Public Domain Dedication waiver (http://creativeco mmons.org/publicdomain/zero/1.0/) applies to the data made available in this article, unless otherwise stated in a credit line to the data. 


\section{Background}

Colorectal cancer is one of the most frequently encountered malignancies and a common cause of cancerrelated death in both men and women [1]. Colonoscopy with the removal of neoplastic polyps has been reported as an effective strategy for preventing deaths from colorectal cancer [2]. Colorectal polyps are routinely sent for pathological evaluation because pathological diagnosis is reliable for determining the appropriate interval until the next surveillance colonoscopy [3]. However, pathological evaluation via endoscopic biopsy or resection may cause adverse events, such as bleeding or perforation, and can incur high medical costs. If optical diagnosis via endoscopy can produce a diagnostic outcome equivalent to that of pathological evaluation, unnecessary removal of colorectal polyps may be avoided with significant reduction in medical costs.

Narrow-band imaging (NBI) is a diagnostic tool for visualizing the vessels and surface patterns of colorectal polyps. Developed in 1999, NBI has been reported to provide valuable information regarding the histology of polyps detected during colonoscopy [4]. Since then, many studies have reported the efficacy of NBI-assisted optical diagnosis of colorectal polyp histology [5-7]. Moreover, NBI-assisted optical diagnosis may enable immediate determination of the appropriate surveillance interval with reduction in the risk of adverse events and health care expenditure [8-10]. In Japan, several magnifying NBI classifications have been developed for use in clinical practice [11-14]. However, magnifying colonoscopy is not widely used globally $[15,16]$. Therefore, there has been a need for a novel NBI classification that does not require optical magnification.

The Narrow-band imaging International Colorectal Endoscopic (NICE) classification, devised by the Colon Tumor NBI Interest Group, uses the color, vessels, and surface patterns of polyps to classify endoscopic findings without optical magnification (Fig. 1) [17-19]. This is the first NBI classification that can be used without optical magnification and is simplified for the ease of use. Previous studies have reported that the NICE classification is helpful for NBI-assisted optical diagnosis of colorectal polyp histology [6, 18, 20-28]. However, most of these studies were conducted to investigate the diagnostic outcomes of optical diagnosis for differentiating between neoplastic and non-neoplastic colorectal lesions. In

\begin{tabular}{|c|c|c|c|}
\hline & Type 1 & Type 2 & Type 3 \\
\hline Color & Same or lighter than background & $\begin{array}{l}\text { Browner relative to background } \\
\text { (verify color arises from vessels) }\end{array}$ & $\begin{array}{c}\text { Brown to dark brown relative to } \\
\text { background; sometimes } \\
\text { patchy whiter areas }\end{array}$ \\
\hline Vessels & $\begin{array}{l}\text { None, or isolated lacy vessels may be } \\
\text { present coursing across the lesion }\end{array}$ & $\begin{array}{l}\text { Brown vessels surrounding } \\
\text { white structures }\end{array}$ & $\begin{array}{l}\text { Has area(s) of disrupted or } \\
\text { missing vessels }\end{array}$ \\
\hline Surface pattern & $\begin{array}{l}\text { Dark or white spots of uniform size, or } \\
\text { homogeneous absence of pattern }\end{array}$ & $\begin{array}{c}\text { Oval, tubular, or branched white } \\
\text { structures surrounded by } \\
\text { brown vessels }\end{array}$ & Amorphous or absent surface pattern \\
\hline Most likely pathology & Hyperplastc/sessile serrated polyp & Adenoma $^{3}$ & Deep submucosal invasive cancer \\
\hline \multicolumn{4}{|l|}{ Endoscopic image } \\
\hline Treatment & Follow-up & Endoscopic resection & Surgical resection \\
\hline
\end{tabular}

Can be applied using colonoscopes with or without optical (zoom) magnification; ${ }^{2}$ These structures (regular or irregular) may represent the pits and the epithelium of crypt opening; ${ }^{3}$ Type 2 consists of Vienna classification type 3, 4 and superfical 5 (all adenoma with either low- or highgrade dysplasia, or with superficial submucosal carcinoma). The presence of high-grade dysplasia or superficial submucosal carcinoma may be suggested by an irregular vessels or surface pattern and is often associated atypical morphology (e.g., depressed area).

Fig. 1 Narrow-band imaging International colorectal endoscopic classification 
contrast, there has been limited research on the diagnostic performance of each type of the NICE classification, and the findings were widely discrepant between the studies; the diagnostic accuracy of the NICE type 1,2 , and 3 was in the range of $36.5-92.6 \%, 80.0-90.7 \%$, and $42.1-96.8 \%$, respectively [16, 25, 29]. Thus, further analyses of data obtained in a clinical setting are required to determine the clinical value of each type of the NICE classification in NBI-assisted optical diagnosis of colorectal polyp histology.

This study aimed to determine the value of the NICE classification in NBI-assisted optical diagnosis of colorectal polyp histology by analyzing endoscopy data accumulated at our facility in a clinical setting. First, we evaluated the diagnostic performance of each type of the NICE classification for determining polyp histology, including the differentiation of neoplastic and non-neoplastic colorectal lesions. Second, we evaluated the reproducibility of the NICE classification for NBI images of colorectal polyps among both experts and non-experts.

\section{Methods}

\section{Study design}

This retrospective single-center study included 543 colorectal lesions (318 patients) with complete data, previously categorized using non-magnifying NBI observation according to the NICE classification. The details of these lesions were accumulated in the endoscopy database at our facility between April 2011 and March 2013. After the exclusion of nine lesions (two patients) that were pathologically diagnosed to be an inflammatory polyp, colitis, or a submucosal lesion, data for 534 colorectal lesions (316 patients) were available for the analysis (Fig. 2). The study was approved by the local ethics committee and conducted in accordance with the ethical standards of the Declaration of Helsinki. The ethics committee approved the use of an opt-out method of obtaining consent, and accordingly, informed consent was obtained via an opt-out option on the website of our facility.

\section{Diagnostic performance of the NICE classification for determining colorectal polyp histology}

During the study period, all colonoscopies were performed by any of the six experienced endoscopists, each of whom had performed more than 3000 colonoscopies and had experience in using magnifying NBI for optical diagnosis but limited experience in using the NICE classification. Non-magnified NBI images were obtained using a high-definition colonoscope (CF-H260AZI, CF-Q260AI, PCF-Q260AZI, or PCF-Q260AI) combined with a standard video processor (EVIS LUCERA

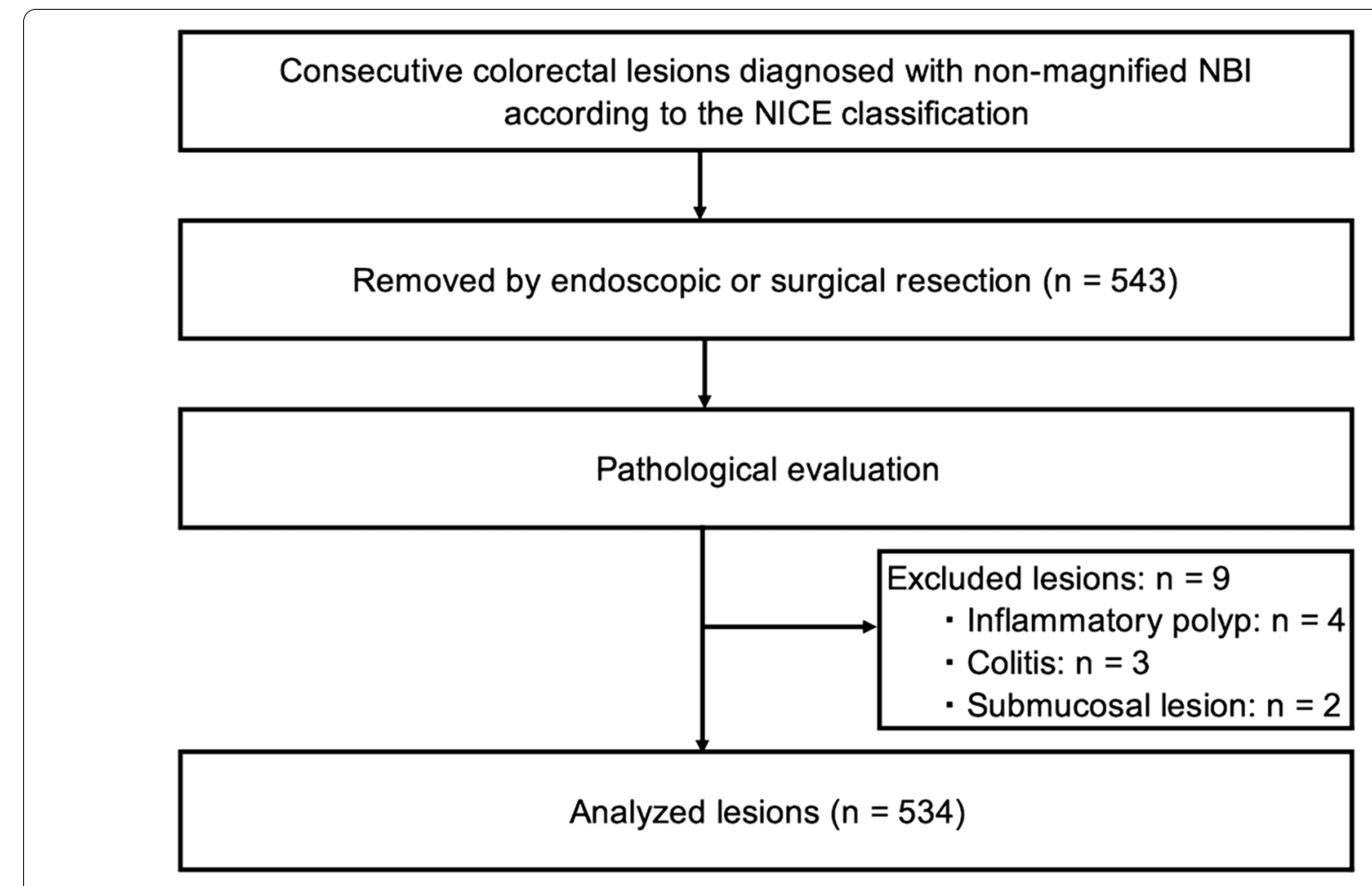

Fig. 2 Study flow. NBI narrow-band imaging, NICE classification narrow-band imaging international colorectal endoscopic classification 
SPECTRUM; Olympus Medical Systems, Tokyo, Japan). After intubation of the cecum, the colonic mucosa was evaluated under white light during the withdrawal of the colonoscope. All polyps detected were documented for size, location, and morphology. Polyp size was estimated by comparison with the span of open biopsy forceps, sheath of the polypectomy snare, or diameter of an open snare placed against the polyp. Polyps were assigned to the cecum, ascending colon including the hepatic flexure, transverse colon including the splenic flexure, descending colon, sigmoid colon, or rectum. The Paris Classification System for Superficial Neoplastic Lesions in the Digestive Tract was used to define polyp morphology [30]. Each polyp identified under white light was further evaluated using NBI without optical magnification and immediately categorized as type 1 , 2 , or 3 according to the NICE classification. All polyps were removed using endoscopic forceps/snare or surgical resection, and the resected specimens were sent for pathological evaluation. The pathological diagnosis was made according to the World Health Organization criteria by two experienced pathologists. Based on the pathological characteristics, each lesion was identified as a hyperplastic polyp (HP), sessile serrated polyp (SSP), low-grade dysplasia (LGD), high-grade dysplasia (HGD; intramucosal cancer), superficial submucosal invasive carcinoma (SM-s; $<1000 \mu \mathrm{m}$ of submucosal invasion), or deep submucosal invasive carcinoma (SM-d; $\geq 1000 \mu \mathrm{m}$ of submucosal invasion).

\section{Inter-observer and intra-observer agreements by experts and non-experts}

We assessed the inter-observer and intra-observer agreements among experts and non-experts to determine the validity and usefulness of this classification after providing a short lecture on the NICE classification. We prepared a set of fine typical NBI images of colorectal polyps of various NICE types for this evaluation. All images were required to be of sufficient clarity to be able to evaluate their color, vessels, and surface pattern and taken with color mode grade 3 and structure enhancement grade A8. After applying these criteria, non-magnified NBI images for 50 of the 534 lesions were selected for the agreement study. Of these 50 lesions, 10 were HP/SSP (type 1), 31 were LGD/ HGD/SM-s (type 2), and 9 were SM-d (type 3). The NBI images of these lesions were arranged in random order. In accordance with the NICE classification, five experts who had performed $>3000$ colonoscopies but had limited experience using the NICE classification and five non-experts (medical students) determined the type of NICE classification for the lesions identified using the
NBI images twice, with a 2-week interval between the evaluations. All observers received a 30-min explanation outlining the concept of the NICE classification before the first evaluation. All observers were blinded to the pathological diagnosis and classification of the lesion. At the second evaluation, they were blinded to the results of their first evaluation.

\section{Statistical analysis}

We evaluated the diagnostic performance (sensitivity, specificity, positive predictive value $[\mathrm{PPV}]$, negative predictive value [NPV], and accuracy) of each type of the NICE classification. Diagnostic performance was also assessed according to whether the polyp measured $<10 \mathrm{~mm}$ or $\geq 10 \mathrm{~mm}$. Inter-observer and intra-observer agreements were analyzed using Cohen's kappa statistic. Multiple comparisons of the kappa value between pairs of observers were conducted as a measure of the interobserver agreement; 10 pairs could be made when a pair was chosen among five observers in each group, and they were compared. The kappa values for each group are presented as the mean, median, and range. The strength of agreement based on the kappa value was defined as follows: poor, $\leq 0.20$; fair, $0.21-0.40$; moderate, $0.41-0.60$; substantial, 0.61-0.80; or excellent, 0.81-1.0. Fisher's exact test was used to compare the diagnostic outcomes between polyps measuring $<10 \mathrm{~mm}$ and those measuring $\geq 10 \mathrm{~mm}$. All statistical analyses were performed using SPSS version 24 (IBM Corp., Armonk, NY, USA) and EZR version 1.27 (Saitama Medical Center, Jichi Medical University, Japan) [31]. All statistical analyses were twosided, and $P$ values $<0.05$ were considered statistically significant.

Table 1 Patients characteristics of the study cohort

\begin{tabular}{ll}
\hline Patients, $\mathrm{n}$ & 316 \\
Median age, years (range) & $69(28-98)$ \\
Sex, male, $\mathrm{n}(\%)$ & $225(71.2)$ \\
Indication for colonoscopy, n (\%) & \\
Polyp surveillance & $77(24.4)$ \\
Endscopic resection & $69(21.8)$ \\
FIT positive & $69(21.8)$ \\
Screening & $28(8.9)$ \\
PET positive & $20(6.3)$ \\
Hematochezia & $14(4.4)$ \\
Anemia & $12(3.8)$ \\
Change of bowel habit & $12(3.8)$ \\
Tumor marker elevation & $5(1.6)$ \\
Others & $10(3.2)$ \\
\hline
\end{tabular}

FIT fecal immunochemical test, PET positron emission tomography 


\section{Results}

\section{Patients and polyp characteristics in the study cohort}

The patient characteristics are summarized in Table 1. The median age was 69 (range 28-98) years. Of the total 316 patients included, $225(71.2 \%)$ were male. The indication for colonoscopy was polyp surveillance in 77 patients

Table 2 Polyp characteristics of the study cohort

\begin{tabular}{ll}
\hline Lesions, $\mathrm{n}$ & 534 \\
Median size, mm (range) & $6(1-100)$ \\
Morphology n (\%) & \\
Ip & $36(6.7)$ \\
Is, Is + Ilc & $424(79.4)$ \\
Ila, Ila + Ilc & $71(13.3)$ \\
Ilc & $3(0.6)$ \\
Location, n (\%) & \\
Right colon (cecum to transvese colon) & $237(44.4)$ \\
Left colon (descending colon to simoid colon) & $237(44.4)$ \\
Rectum & $60(11.2)$ \\
Pathological diagnosis, n (\%) & \\
HP/SSP & $43(8.0)$ \\
LDG & $427(80.0)$ \\
HGD & $48(9.0)$ \\
SM-s & $5(0.9)$ \\
SM-d & $11(2.1)$ \\
\hline
\end{tabular}

HP hypeplastic polyp, SSP sessile serrated polyp, LDG low-grade dyplasia, $H G D$ high-grade dysplasia, $S M$-s superfical submucosal invasive carcinoma $(<1000 \mathrm{~mm}), S M-d$ deep submucosal invasive carcinoma $(\geq 1000 \mathrm{~mm})$
(24.4\%), endoscopic resection in $69(21.8 \%)$, positivity of a fecal immunochemical test in $69(21.8 \%)$, screening in $28(8.9 \%)$, and positivity on positron emission tomography in 20 (6.3\%).

The polyp characteristics are summarized in Table 2. The median size was 6 (range 1-100) mm. In total, 237 lesions (44.4\%) were in the right colon, 237 (44.4\%) in the left colon, and $60(11.2 \%)$ in the rectum. Pathological evaluation revealed that 491 (92.0\%) were neoplastic polyps (LGD/HGD/SM-s/SM-d).

\section{Relationship between the NICE classification and polyp histology}

The relationship between the NICE classification and polyp histology stratified by the polyp size is presented in Table 3. Independent of size, 39 lesions were diagnosed as NICE type 1 and 37 (94.8\%) were HP/SSP; of 484 lesions diagnosed as NICE type 2, 476 (98.3\%) were LDG/HDG/ SM-s; and of 11 lesions diagnosed as NICE type 3 and 9 (81.8\%) were SM-d.

\section{Diagnostic performance}

The diagnostic performance for each NICE classification type when stratified by polyp size is presented in Table 4. The sensitivity, specificity, PPV, NPV, and accuracy were $86.0 \%, 99.6 \%, 94.9 \%, 98.8 \%$, and $98.5 \%$ for NICE type 1 ; 99.2\%, $85.2 \%, 98.3 \%, 92.0 \%$, and $97.8 \%$ for NICE type 2 ;

Table 3 Relationship between each type in the NICE classification and polyp histology stratified by polyp size

\begin{tabular}{|c|c|c|c|c|c|c|c|}
\hline \multirow{3}{*}{$\begin{array}{l}\text { Type of } \\
\text { classification }\end{array}$} & & \multirow{3}{*}{$\mathrm{n}$} & \multicolumn{5}{|c|}{ Histological findings, $\mathrm{n}(\%)$} \\
\hline & & & \multirow{2}{*}{$\mathrm{HP} / \mathrm{SSP}$} & \multirow{2}{*}{ LGD } & \multirow{2}{*}{ HGD } & \multicolumn{2}{|c|}{ Carcinoma } \\
\hline & & & & & & SM-s & SM-d \\
\hline \multirow{3}{*}{ Type 1} & $<10 \mathrm{~mm}$ & 28 & :-ー-ー-ー & $2(7.1)$ & $0(0.0)$ & $0(0.0)$ & $0(0.0)$ \\
\hline & $\geq 10 \mathrm{~mm}$ & 11 & $11(100.0)$ & $0(0.0)$ & $0(0.0)$ & $0(0.0)$ & $0(0.0)$ \\
\hline & All size & 39 & $37(94.8)$ & $2(5.2)$ & $0(0.0)$ & $0(0.0)$ & $0(0.0)$ \\
\hline \multirow[t]{3}{*}{ Type 2} & $<10 \mathrm{~mm}$ & 337 & $6(1.8)$ & $324(96.1)$ & $6(1.8)$ & $1(0.3)$ & $0(0.0)$ \\
\hline & $\geq 10 \mathrm{~mm}$ & 147 & $0(0.0)$ & $101(68.7)$ & 41 (27.9) & $3(2.0)$ & $2(1.4)$ \\
\hline & All size & 484 & $6(1.3)$ & $425(87.8)$ & $47(9.7)$ & $4(0.8)$ & $2(0.4)$ \\
\hline \multirow[t]{3}{*}{ Type 3} & $<10 \mathrm{~mm}$ & 3 & $0(0.0)$ & $0(0.0)$ & $0(0.0)$ & $1(33.3)$ & $2(66.7)$ \\
\hline & $\geq 10 \mathrm{~mm}$ & 8 & $0(0.0)$ & $0(0.0)$ & $0(0.0)$ & $1(12.5)$ & $7(87.5)$ \\
\hline & All size & 11 & $0(0.0)$ & $0(0.0)$ & $0(0.0)$ & $2(18.2)$ & $9(81.8)$ \\
\hline Total & & 534 & $43(8.0)$ & $427(80.0)$ & $47(8.8)$ & $6(1.1)$ & $11(2.1)$ \\
\hline
\end{tabular}

Surrounded by dotted line: most like histology of each type in the NICE classification

NICE classification Narrow-band imaging international colorectal endoscopic classification, HP hypeplastic polyp, SSP sessile serrated polyp, LDG low-grade dyplasia, $H G D$ high-grade dysplasia, $S M$-s superfical submucosal invasive carcinoma ( $<1000 \mathrm{~mm}$ ), $S M-d$ deep submucosal invasive carcinoma ( $\geq 1000 \mathrm{~mm}$ ) 
Table 4 Diagnostic performance of each type in the NICE clasification stratified by polyp size

\begin{tabular}{|c|c|c|c|c|c|}
\hline Type of classification & Sensitivity (\%) (95\% CI) & Specificity (\%) (95\% Cl) & PPV (\%) $(95 \%$ CI) & NPV (\%) (95\% Cl) & Accuracy (\%) $(95 \% \mathrm{Cl})$ \\
\hline \multicolumn{6}{|l|}{ Type 1} \\
\hline$<10 \mathrm{~mm}$ & $81.2(63.6-92.8)$ & 99.4 (97.9-99.9) & $92.9(76.5-99.1)$ & $98.2(96.2-99.3)$ & $97.8(95.8-99.1)$ \\
\hline$\geq 10 \mathrm{~mm}$ & $100.0(61.5-100.0)$ & $100.0(96.5-100.0)$ & $100.0(61.5-100.0)$ & $100.0(96.5-100.0)$ & $100.0(96.7-100.0)$ \\
\hline All size & $86.0(72.1-94.7)$ & $99.6(98.5-100.0)$ & $94.9(82.7-99.4)$ & $98.8(97.4-99.6)$ & $98.5(97.1-99.4)$ \\
\hline \multicolumn{6}{|l|}{ Type 2} \\
\hline$<10 \mathrm{~mm}$ & 99.1 (97.4-99.8) & $82.4(65.5-93.2)$ & $98.2(96.2-99.3)$ & $90.3(74.2-98.0)$ & $97.6(95.4-98.9)$ \\
\hline$\geq 10 \mathrm{~mm}$ & $99.3(96.2-100.0)$ & $90.0(68.3-98.8)$ & 98.6 (95.2-99.8) & $94.7(74.0-99.9)$ & $98.2(94.8-99.6)$ \\
\hline All size & 99.2 (97.9-99.8) & $85.2(72.9-93.4)$ & $98.3(96.8-99.3)$ & $92.0(80.8-97.8)$ & $97.8(96.1-98.8)$ \\
\hline \multicolumn{6}{|l|}{ Type 3} \\
\hline$<10 \mathrm{~mm}$ & $100.0(9.4-100.0)$ & $99.7(98.5-100.0)$ & $66.7(9.4-99.2)$ & $100.0(98.5-100.0)$ & $99.7(98.5-100.0)$ \\
\hline$\geq 10 \mathrm{~mm}$ & $77.8(40.0-97.2)$ & $99.4(96.5-100.0)$ & $87.5(47.3-99.7)$ & 98.7 (95.5-99.8) & $98.2(94.8-99.6)$ \\
\hline All size & $81.8(48.2-97.7)$ & $99.6(98.6-100.0)$ & $81.8(48.2-97.7)$ & $99.6(98.6-100.0)$ & $99.3(98.1-99.8)$ \\
\hline \multicolumn{6}{|l|}{$\begin{array}{l}\text { Determination of neo- } \\
\text { plastic polyp (Type } \\
2 / 3 \text { ) }\end{array}$} \\
\hline$<10 \mathrm{~mm}$ & 99.4 (97.9-99.9) & $81.2(63.6-92.8)$ & $98.2(96.2-99.3)$ & $92.9(76.5-99.1)$ & $97.8(95.8-99.1)$ \\
\hline$\geq 10 \mathrm{~mm}$ & $100.0(96.5-100.0)$ & $100.0(61.5-100.0)$ & $100.096 .5-100.0)$ & $100.0(61.5-100.0)$ & $100.0(96.7-100.0)$ \\
\hline All size & $99.6(98.5-100.0)$ & $86.0(72.1-94.7)$ & 98.8 (97.4-99.6) & 94.9 (82.7-99.4) & $98.5(97.1-99.4)$ \\
\hline
\end{tabular}

The sensitivity, specificity, PPV, NPV, and accuracy of each type do not differ significantly between polyp sized $<10 \mathrm{~mm}$ and $\geq 10 \mathrm{~mm}$

NICE classification narrow-band imaging international colorectal endoscopic classification, $C l$ confidence interval, $P P V$ positive predictive value, NPV negative predictive value

Table 5 Inter-observer and intra-observer agreements of experts and non-experts for the NICE classification

\begin{tabular}{llll}
\hline & \multicolumn{2}{l}{ Kappa value } & \\
\cline { 2 - 4 } & Average & Median & Range \\
\hline $\begin{array}{l}\text { Inter-observer agreement } \\
\quad \text { Experts }\end{array}$ & 0.86 & 0.86 & $0.76-0.93$ \\
$\quad$ Non-experts & 0.59 & 0.62 & $0.47-0.63$ \\
Intra-observer agreement & & & \\
$\quad$ Experts & 0.82 & 0.83 & $0.68-0.90$ \\
$\quad$ Non-experts & 0.63 & 0.63 & $0.54-0.70$ \\
\hline
\end{tabular}

Observers were experienced with $>3000$ colonoscopies

Observers were medical students

NICE classification Narrow-band imaging international colorectal endoscopic classification

and $81.8 \%, 99.6 \%, 81.8 \%, 99.6 \%$, and $99.3 \%$ for NICE type 3 , respectively. Neoplastic lesions (NICE type 2/3) could be determined with a sensitivity, specificity, PPV, NPV, and accuracy of $99.6 \%, 86.0 \%, 98.8 \%, 94.9 \%$, and $98.5 \%$, respectively. After stratification by polyp size, the sensitivity, specificity, PPV, NPV, and accuracy of diagnosis of each type did not differ significantly according to whether the polyp measured $<10 \mathrm{~mm}$ or $\geq 10 \mathrm{~mm}$.

\section{Inter-observer and intra-observer agreements}

Inter-observer and intra-observer agreements were assessed using Cohen's kappa values (Table 5). At the first reading, the average and median kappa values for inter-observer agreement were 0.86 and 0.86 (range 0.76-0.93) for experts and 0.59 and 0.62 (range 0.47-0.63) for non-experts, respectively, and those for intra-observer agreement were 0.82 and 0.83 (range $0.68-0.90$ ) for experts and 0.63 and 0.63 (range 0.54$0.70)$ for non-experts, respectively.

\section{Discussion}

Two major findings of this study were as follows: First, this study demonstrated a good diagnostic outcome of each type of the NICE classification for determining polyp histology by evaluating the endoscopy data accumulated in a clinical setting. The sensitivity, specificity, PPV, NPV, and accuracy for diagnosing each NICE type did not differ significantly according to the polyp size. Second, there were good inter-observer and intraobserver agreements between non-experts as well as experts, confirming the reproducibility of the NICE classification.

The NICE classification had a specificity, NPV, and accuracy of $>90 \%$ for the diagnosis of type 1 and 3 lesions. These findings indicate that NICE types 1 and 3 are definite indicators of the most likely histology with significant diagnostic outcomes. Therefore, the NICE classification is useful for identifying polyps that do not need to be removed and those that warrant surgical resection $[18,19,28]$. For a diagnosis of NICE type 
2 , the NPV and accuracy were $>90 \%$, but the specificity was $85.2 \%$. This may be because NICE type 2 lesions show various pathological features, ranging from LGD to SM-s. However, optical diagnosis is important for differentiation between LGD/HGD/SM-s and SM-d lesions in clinical practice to determine the appropriate therapeutic strategy. The NICE classification will allow us to distinguish between LGD/HGD/SM-s lesions, which can be treated curatively via endoscopic resection, and SM-d lesions, which require surgical resection. Furthermore, the specificity, NPV, and accuracy for the diagnosis of NICE type $2 / 3$ were $86.0 \%$. $94.9 \%$ and $98.5 \%$, respectively, which indicates that the NICE classification has good diagnostic performance for determining neoplastic polyps. Based on these results, the NICE classification can be considered a useful tool for determining the most likely histology of colorectal polyps in clinical practice.

These results are mostly superior to those of previous studies that investigated the application of each type of the NICE classification $[16,25,29]$. There are two likely reasons for the differences in the findings between these studies and our study. First, the diagnostic outcomes using the NICE classification were investigated based on examination by endoscopists skilled in NBI-assisted optical diagnostic systems. Although these endoscopists had limited experience in using the NICE classification before participating in this study, they had an experience of using magnifying NBI routinely, such as the Hiroshima classification [11] or Sano classification [12]. The NICE classification is similar to these classifications regarding the diagnostic strategy using the color, vessels, or surface patterns of colorectal polyps. Thus, the endoscopists might also be skilled in the NBI-assisted diagnostic strategy of the NICE classification. Wang et al. have reported that a group of highly experienced endoscopists who had routinely used magnifying NBI for $>5$ years showed excellent diagnostic outcomes in NBI-assisted optical diagnosis using the NICE classification; the sensitivity, specificity, and accuracy were as follows: $84.6 \%$, $94.9 \%$, and $93.9 \%$ in type $1,91.4 \%, 86.3 \%$, and $90.7 \%$ in type $2,91.7 \%, 97.0 \%$, and $96.8 \%$ in type 3 , respectively [16]. Second, the characteristics of the lesions may have influenced the diagnostic outcomes of our study. The percentages of HP/SSP (8.0\%) and SM-d (2.1\%) lesions in the present study were small. The data used had been obtained in a clinical setting; therefore, type 1 lesions in the rectosigmoid colon diagnosed as HP were not removed, and SM-d lesions are rarely encountered during routine colonoscopy in clinical practice. Consequently, almost all lesions were classified as NICE 2 type, contributing to this study's diagnostic outcomes.

To ensure the generalizability of the NICE classification, we assessed the inter-observer and intra-observer agreements using 50 NBI images without optical magnification after providing experts and non-experts a lecture demonstrating the use of this classification. The global acceptance of NBI-assisted optical diagnosis in clinical practice will require a simple, standardized NBI classification that can be easily understood and applied by non-experts and experts. The NICE classification was developed with the guiding principles of simplicity and ease of use in mind. In the present study, good agreement was demonstrated among both non-experts and experts. Therefore, the NICE classification can be accepted globally and used by endoscopists with different experience level.

Several studies have reported that NBI with optical magnification enables endoscopists to accurately determine colorectal polyp histology. A meta-analysis of 27 studies on NBI magnification reported that the pooled sensitivity, specificity, PPV, and NPV for predicting neoplastic polyps were $95.8 \%, 85.8 \%, 92.9 \%$, and $91.5 \%$, respectively [32]. These values are not significantly different from those obtained in our study. Furthermore, the use of optical zoom magnifying colonoscopes is not yet widespread globally in clinical practice $[15,16]$. Therefore, using the NICE classification without optical magnification might be more convenient and practical for determining colorectal polyp histology [23].

There remains an unanswered question in this study. A recent study has highlighted NBI features that may be used to distinguish SSP from HP; the characteristic NBI findings for SSP include the red cap sign, a cloudlike surface, dilated and branched vessels, and expanded crypt openings [33]. When combined with these findings, the NICE classification may improve our ability to diagnose SSPs. However, the present study was performed using data obtained before these characteristic findings of SSP were recognized, and endoscopists were not asked to classify type 1 lesions as HP or SSP. Therefore, it is not possible to conclude the diagnostic performance of the NICE classification for SSP based on our current findings.

This study has some limitations. First, it had a singlecenter design. Second, it did not include a control group, such as NBI or chromoendoscopy with optical magnification. Therefore, to provide solid evidence for the value of the NICE classification, studies that include a control group and a larger number of individuals are required. Third, the confidence level of optical diagnosis could not be assessed because the data analyzed were obtained retrospectively from information accumulated in clinical practice. Fourth, we did not remove all type 1 lesions during colonoscopy, which may have introduced a degree of sampling bias. The data analyzed were obtained in a clinical setting, and type 1 lesions diagnosed as HP in 
the rectosigmoid colon were not removed. Our study focused on the resected lesions, and unresectable lesions could not be evaluated. Therefore, it is likely that sampling biases resulted in a low percentage of type 1 lesions, thereby influencing the results of this study. Finally, the data used in this study were accumulated between 2011 and 2013, and more recent data could not be used. However, all procedures were performed using a highdefinition colonoscope combined with a standard video processor, similar to the equipment used in more recent studies. Therefore, the diagnostic outcomes of the NICE classification documented in this study can be considered to be almost equivalent to those reported in any investigations using more recent data.

\section{Conclusions}

This study found that the use of the NICE classification provided good diagnostic outcomes when determining colorectal polyp histology in a clinical setting, regardless of the polyp size. Furthermore, it demonstrated favorable reproducibility by non-experts as well as by experts. The NICE classification is practical for use without magnifying colonoscopy because it is simple and easy to apply and has high accuracy for diagnosis and therapeutic decision-making.

\footnotetext{
Abbreviations

NBI: Narrow-band imaging; NICE: Narrow-band imaging international colorectal endoscopic; HP: Hyperplastic polyp; SSP: Sessile serrated polyp; LGD: Low-grade dysplasia; HGD: High-grade dysplasia; SM-s: Superficial submucosal invasive carcinoma; SM-d: Deep submucosal invasive carcinoma; PPV: Positive predictive value; NPV: Negative predictive value.
}

\section{Acknowledgements}

The authors thank the medical staff members of the Department of Endoscopy, Mie University Hospital, for their contributions to this work. We would like to also thank Editage (www.editage.com) for English language editing.

\section{Authors' contributions}

YH contributed to the study's conception and design. YH, KT, MK, NH, RY, and $Y T$ contributed to the data collection. TY contributed to the statistical analyses. The first draft of the manuscript was written by $\mathrm{YH}$, and all the authors reviewed the previous versions of the manuscript. All authors read and approved the final manuscript.

\section{Funding}

The authors did not receive any funding.

\section{Availability of data and materials}

All data generated and analyzed during this study are included in this published article.

\section{Declarations}

\section{Ethics approval and consent to participate}

The study protocol was approved by the ethics committee of Mie University Hospital (approval number 2013-1334). The study was conducted ethically in accordance with the approved protocol and ethical guidelines of the Declaration of Helsinki. The ethics committee approved the use of an opt-out method of obtaining consent, and accordingly, informed consent was obtained via an opt-out option on the website of our facility.

\section{Consent for publication}

Not applicable.

\section{Competing interests}

The authors declare that they have no competing interests.

\section{Author details}

${ }^{1}$ Department of Gastroenterology and Hepatology, Mie University Hospital, 2-174 Edobashi, Tsu, Mie 514-8507, Japan. ${ }^{2}$ Department of Endoscopy, Mie University Hospital, Tsu, Japan. ${ }^{3}$ Department of Medical Innovation, Osaka University Hospital, Suita, Japan.

Received: 18 March 2021 Accepted: 3 August 2021

Published online: 28 August 2021

\section{References}

1. Bray F, Ferlay J, Soerjomataram I, Siegel RL, Torre LA, Jemal A. Global cancer statistics 2018: GLOBOCAN estimates of incidence and mortality worldwide for 36 cancers in 185 countries. CA Cancer J Clin. 2018;68:394-424

2. Zauber AG, Winawer SJ, O'Brien MJ, Lansdorp-Vogelaar I, van Ballegooijen M, Hankey BF, et al. Colonoscopic polypectomy and long-term prevention of colorectal-cancer deaths. N Engl J Med. 2012;366:687-96.

3. Rex DK, Boland CR, Dominitz JA, Giardiello FM, Johnson DA, Kaltenbach $\mathrm{T}$, et al. Colorectal cancer screening: recommendations for physicians and patients from the U.S. multi-society task force on colorectal cancer. Gastrointest Endosc. 2017:86:18-33.

4. Machida H, Sano Y, Hamamoto Y, Muto M, Kozu T, Tajiri H, et al. Narrowband imaging in the diagnosis of colorectal mucosal lesions: a pilot study. Endoscopy. 2004;36:1094-8.

5. Rex DK. Narrow-band imaging without optical magnification for histologic analysis of colorectal polyps. Gastroenterology. 2009;136:1174-81.

6. Wallace MB, Crook JE, Coe S, Ussui V, Staggs E, Almansa C, et al. Accuracy of in vivo colorectal polyp discrimination by using dual-focus highdefinition narrow-band imaging colonoscopy. Gastrointest Endosc. 2014;80:1072-87

7. van de Wetering AJP, Meulen LWT, Bogie RMM, van der Zander QEW, Reumkens A, Winkens B, et al. Optical diagnosis of diminutive polyps in the Dutch bowel cancer screening program: Are we ready to start? Endosc Int Open. 2020;8:E257-65.

8. Ignjatovic A, East JE, Suzuki N, Vance M, Guenther T, Saunders BP. Optical diagnosis of small colorectal polyps at routine colonoscopy (Detect InSpect ChAracterise Resect and Discard; DISCARD trial): a prospective cohort study. Lancet Oncol. 2009;10:1171-8.

9. Paggi S, Rondonotti E, Amato A, Terruzzi V, Imperiali G, Mandelli G, et al. Resect and discard strategy in clinical practice: a prospective cohort study. Endoscopy. 2012;44:899-904.

10. Repici A, Hassan C, Radaelli F, Occhipinti P, De Angelis C, Romeo F, et al. Accuracy of narrow-band imaging in predicting colonoscopy surveillance intervals and histology of distal diminutive polyps: results from a multicenter, prospective trial. Gastrointest Endosc. 2013;78:106-14.

11. Kanao H, Tanaka S, Oka S, Hirata M, Yoshida S, Chayama K. Narrow-band imaging magnification predicts the histology and invasion depth of colorectal tumors. Gastrointest Endosc. 2009;69(3 Pt 2):631-6.

12. Sano Y, Ikematsu H, Fu Kl, Emura F, Katagiri A, Horimatsu T, et al. Meshed capillary vessels by use of narrow-band imaging for differential diagnosis of small colorectal polyps. Gastrointest Endosc. 2009;69:278-83.

13. Wada Y, Kudo SE, Kashida H, Ikehara N, Inoue H, Yamamura F, et al. Diagnosis of colorectal lesions with the magnifying narrow-band imaging system. Gastrointest Endosc. 2009;70:522-31.

14. Saito S, Tajiri H, Ohya T, Nikami T, Aihara H, Ikegami M. The benefit of using narrow-band imaging systems for observation of capillary networks before determining of treatments for early colon cancer. Dig Endosc. 2011;23(Suppl 1):120-5.

15. Sumimoto K, Tanaka S, Shigita K, Hirano D, Tamaru Y, Ninomiya Y, et al. Clinical impact and characteristics of the narrow-band imaging 
magnifying endoscopic classification of colorectal tumors proposed by the Japan NBI Expert Team. Gastrointest Endosc. 2017;85:816-21.

16. Wang Y, Li WK, Wang YD, Liu KL, Wu J. Diagnostic performance of narrowband imaging international colorectal endoscopic and Japanese narrowband imaging expert team classification systems for colorectal cancer and precancerous lesions. World J Gastrointest Oncol. 2021;13:58-68.

17. Tanaka S, Sano Y. Aim to unify the narrow band imaging (NBI) magnifying classification for colorectal tumors: current status in Japan from a summary of the consensus symposium in the 79th annual meeting of the Japan Gastroenterological Endoscopy Society. Dig Endosc. 2011;23(Suppl 1):131-9.

18. Hewett DG, Kaltenbach T, Sano Y, Tanaka S, Saunders BP, Ponchon T, et al. Validation of a simple classification system for endoscopic diagnosis of small colorectal polyps using narrow-band imaging. Gastroenterology. 2012;143:599-607.

19. Hayashi N, Tanaka S, Hewett DG, Kaltenbach TR, Sano Y, Ponchon T, et al. Endoscopic prediction of deep submucosal invasive carcinoma: validation of the narrow-band imaging international colorectal endoscopic (NICE) classification. Gastrointest Endosc. 2013;78:625-32.

20. Ladabaum U, Fioritto A, Mitani A, Desai M, Kim JP, Rex DK, et al. Real-time optical biopsy of colon polyps with narrow band imaging in community practice does not yet meet key thresholds for clinical decisions. Gastroenterology. 2013;144:81-91.

21. Seref Koksal A, Yildiz H, Taskiran I, Turhan N, Oztas E, Torun S, et al. Low magnification narrow band imaging by inexperienced endoscopists has a high accuracy in differentiation of colon polyp histology. Clin Res Hepatol Gastroenterol. 2014;38:763-9.

22. Iwatate M, Sano Y, Hattori S, Sano W, Hasuike N, Ikumoto T, et al. The addition of high magnifying endoscopy improves rates of high confidence optical diagnosis of colorectal polyps. Endosc Int Open. 2015;3:E140-5.

23. Kim JJ, Hong KS, Kim JS, Jung HC. A randomized controlled clinical study comparing the diagnostic accuracy of the histologic prediction for colorectal polyps depending on the use of either magnified or nonmagnified narrow band imaging. Clin Endosc. 2015;48:528-33.

24. Rees CJ, Rajasekhar PT, Wilson A, Close H, Rutter MD, Saunders BP, et al. Narrow band imaging optical diagnosis of small colorectal polyps in routine clinical practice: the detect inspect characterise resect and discard 2 (DISCARD 2) study. Gut. 2017;66:887-95.

25. Patrun J, Okresa L, Ivekovic H, Rustemovic N. Diagnostic accuracy of NICE classification system for optical recognition of predictive morphology of colorectal polyps. Gastroenterol Res Pract. 2018;2018:7531368.

26. Zhang QW, Zhang JJ, Yang AM, Sheng JQ, Liu YL, Li ZS, et al. Feasibility of using narrow band imaging international colorectal endoscopic classification for diagnosing colorectal neoplasia in China: a multicenter pilot observational study. J Dig Dis. 2020;21:88-97.

27. Sha J, Wang P, Sang N, Zhang H, Yang A, Chen L, et al. The value of three narrow-band imaging model in the diagnosis of small colorectal polyps. Sci Rep. 2020;10:22032.

28. Puig I, Lopez-Ceron M, Arnau A, Rosinol O, Cuatrecasas M, Herreros-deTejada A, et al. Accuracy of the narrow-band imaging international colorectal endoscopic classification system in identification of deep invasion in colorectal polyps. Gastroenterology. 2019;156:75-87.

29. Cocomazzi F, Gentile M, Perri F, Bossa F, Merla A, Ippolito A, et al. Accuracy and inter-observer agreement of the nice and kudo classifications of superficial colonic lesions: a comparative study. Int J Colorectal Dis. 2021:36:1561-8.

30. Participants in the Paris Workshop. The Paris endoscopic classification of superficial neoplastic lesions: esophagus, stomach and colon: November 30 to December 1, 2002. Gastrointest Endosc. 2003;58:S3-43.

31. Kanda Y. Investigation of the freely available easy-to-use software "EZR" for medical statistics. Bone Marrow Transplant. 2013:48:452-8.

32. Mason SE, Poynter L, Takats Z, Darzi A, Kinross JM. Optical technologies for endoscopic real-time histologic assessment of colorectal polyps: a meta-analysis. Am J Gastroenterol. 2019;114:1219-30.

33. Sano W, Hirata D, Teramoto A, Iwatate M, Hattori S, Fujita M, et al. Serrated polyps of the colon and rectum: Remove or not? World J Gastroenterol. 2020:26:2276-85.

\section{Publisher's Note}

Springer Nature remains neutral with regard to jurisdictional claims in published maps and institutional affiliations.
Ready to submit your research? Choose BMC and benefit from:

- fast, convenient online submission

- thorough peer review by experienced researchers in your field

- rapid publication on acceptance

- support for research data, including large and complex data types

- gold Open Access which fosters wider collaboration and increased citations

- maximum visibility for your research: over $100 \mathrm{M}$ website views per year

At BMC, research is always in progress.

Learn more biomedcentral.com/submissions 